\title{
Emotional health and self-esteem among adolescents in Malaysian orphanages
}

\begin{abstract}
This study aimed to assess the prevalence and risk factors of depression, anxiety, stress and low self-esteem among institutional Malaysian adolescents. This cross-sectional descriptive study included 287 adolescents aged 12-18 years living in six selected orphan homes. Study's instruments included Socio-demographic questionnaire, validated Malay version of Depression Anxiety Stress Scale-21 and Rosenberg Self-Esteem Scale. The findings revealed that $85.2,80.1$ and $84.7 \%$ of participants had depression, anxiety and stress respectively. Females were more likely to be depressed. Furthermore, anxiety was significantly associated with race and age but no significant associations between stress and the demographic factors were found. The study also showed that $70.8 \%$ of males and $69.2 \%$ of females had low selfesteem and the self-esteem was associated with depression, anxiety and stress.Therefore, mental health problems are very common among adolescents in Malaysian orphanages. Results reveal the urgency of immediate actions to reduce the mental health problems among Malaysian institutional adolescents.
\end{abstract}

Keyword: Emotional health; Malaysian adolescents; Malaysian orphanages; Mental health; Self-esteem 